Check for updates

Cite this: RSC Adv., 2021, 11, 11388

Received 16th January 2021

Accepted 1st March 2021

DOI: $10.1039 / \mathrm{d} 1 \mathrm{ra00400j}$

rsc.li/rsc-advances

\section{The cross-talk between lateral sheet dimensions of pristine graphene oxide nanoparticles and $\mathrm{Ni}^{2+}$ adsorption $\uparrow$}

\author{
Majdoleen Atawneh, ${ }^{a}$ Sami Makharza, (D) *b Sahar Zahran, ${ }^{a}$ Kariman Titi, ${ }^{a}$ \\ Fahed Takrori ${ }^{\mathrm{a}}$ and Silke Hampel $^{\mathrm{C}}$
}

\begin{abstract}
This study investigated the removal of nickel(I) ions by using two sizes of graphene oxide nanoparticles (GO - $450 \mathrm{~nm}$ and GO - $200 \mathrm{~nm}$ ). The thickness and lateral sheet dimensions of GO are considered to be an important adsorbent and promising method for sufficient removal of metals like nickel, lead, copper, etc. The graphite oxide was prepared by oxidation-reduction reaction (Hummers method), and the final product was labelled as GO - $450 \mathrm{~nm}$. A tip sonicator was used to reduce the size of particles to $200 \mathrm{~nm}$ under controlled conditions (time and power of sonication). FTIR spectroscopy shows that both sizes of GO particles contain several types of oxygen groups distributed onto the surface of GO particles. Scanning electron microscopy (SEM) and the statistical analysis confirmed the formation of these two sizes of GO particles. The GO - $200 \mathrm{~nm}$ performed better removal of Ni(॥) compared with GO $450 \mathrm{~nm}$, due to more surfaces being available. The adsorption capacity of GO particles increased drastically from $45 \mathrm{mg} \mathrm{g}^{-1}$ to $75 \mathrm{mg} \mathrm{g}^{-1}$ for GO $-450 \mathrm{~nm}$ and GO - $200 \mathrm{~nm}$ respectively, these values were carried out after $2 \mathrm{~h}$ of incubation. The kinetics of adsorption and several parameters like initial concentration at equilibrium, $\mathrm{pH}$, temperature, and adsorbent dose are controlled and studied by using UV-visible spectroscopy. The results indicated a significant potential of GO - $200 \mathrm{~nm}$ as an adsorbent for $\mathrm{Ni}($ II) ion removal. An additional experiment was performed to estimate the surface area of GO $450 \mathrm{~nm}$ and GO $-200 \mathrm{~nm}$, the results show that the surface areas of GO $-450 \mathrm{~nm}$ and GO $-200 \mathrm{~nm}$ are $747.8 \mathrm{~m}^{2} \mathrm{~g}^{-1}$ and $1052.2 \mathrm{~m}^{2} \mathrm{~g}^{-1}$ respectively.
\end{abstract}

\section{Introduction}

Graphene oxide (GO) has been investigated as an extraordinary next-generation adsorbent in water and wastewater purification..$^{1-3}$ The neat structure and outstanding physicochemical characteristics of GO have attracted enormous attention from researchers for use in several fields of technology, such as energy, biology, medicine, and water., ${ }^{2,-14}$ GO is a twodimensional layer of $\mathrm{sp}^{2}$ hybridized carbon atoms decorated with abundant oxygen groups like carboxyl, hydroxyl, epoxy, etc., these groups have the ability to bind with organic and inorganic substances with both chemical and/or physical interactions. Moreover due to its highly hydrophilic surfaces, open flake morphology and high adsorption capacity towards different metallic ions, organic and inorganic materials, several

${ }^{a}$ Faculty of Science and Technology, Department of Chemistry, Hebron University, P.O. Box 40, Hebron, West Bank, Palestine

${ }^{b}$ College of Medicine, Hebron University, P.O. Box 40, Hebron, West Bank, Palestine. E-mail:samim@hebron.edu

${ }^{c}$ IFW Dresden, Germany

$\dagger$ Electronic supplementary information (ESI) available. See DOI: 10.1039/d1ra00400j reports have been focused on GO as a promising nanosystem in wastewater treatment. It exhibits no obvious toxicity under low dose $(c a .0 .2 \mathrm{mg})$ and medium dose $(c a .0 .2-0.25 \mathrm{mg}) \cdot{ }^{15-17}$

Heavy metals such as cadmium, cobalt, lead, nickel are nonbio-degradable and cause various diseases and disorders. Nickel is a transition metal ion that has four oxidation states $(+1$, $+2,+3$, and +4 ), it is widely used in industry such as mining, smelting, textiles, fertilizer, electroplating, battery manufacturing, and pigment production. At high concentrations, $\mathrm{Ni}^{2+}$ may lead to stern damage of vital organs such as lungs, kidneys, gastrointestinal irritation, and lung and bone cancers.

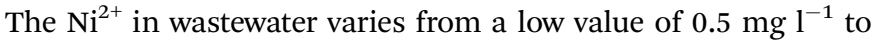
a high value of $1000 \mathrm{mg} \mathrm{l}^{-1}$. The maximum permissible safe limit of $\mathrm{Ni}^{2+}$ with industrial effluents into land water is $3 \mathrm{mg} \mathrm{l.,18,19}$ Innovative approaches for treating industrial wastewater including heavy metals often involve new technologies for reducing poisonousin order to gather technology-based treatment standards. The incorporation of nanoparticles such as functionalized graphene and carbon nanotubes into water purification technologies against the removal of heavy metals appears as a very dynamic branch of nanotechnology. Nanoparticles owe their potential to the high specific surface area and surface reactivity compared to conventional substances. Depending on 
the mechanism of uptake, nanoparticles can be destined to establish high selectivity against various types of pollutants.Graphene oxide has a very extensive advantage in treating various heavy metal ions from aqueous solutions, such as lead (Pb(II)), ${ }^{\mathbf{2 0 , 2 1}}$ copper $(\mathrm{Cu}(\mathrm{II})),{ }^{22,23}$ cobalt (Co(II)), ${ }^{24}$ cadmium (Cd(II)), ${ }^{22}$ chromium $(\mathrm{Cr}(\mathrm{VI})){ }^{25}$ Moreover, GO functionalized by using organic molecules inorder to enhance the surface selectivity of pollutants. ${ }^{22,26,27}$

Nowadays, an extensive research on the facile synthesis of $2 \mathrm{D}$ carbon nanomaterials with inorganic substances derived from MOF precursors for various applications. ${ }^{28-30}$ The determination of heavy metal ions in water can be achieved using various methods. The simple and facile method is a chemical reagent method such as (4-(2-pyridylazo) resorcinol) which depends on changes in color when reacting with heavy metal ions. The more precise detection method is carried out using instruments like inductively coupled plasma-mass spectrometry (ICP-MS), atomic absorption spectrophotometer (AAS), and X-ray fluorescence spectrometry (XRF). However, those techniques require additional chemicals, expensive equipment, and trained users. Thus, in this article, ultraviolet/visible (UV/VIS) spectroscopy method was employed as a non-destructive method for the detection of nickel(II) without chemical reagents. ${ }^{31}$

To the best of our knowledge, no studies have been conducted to investigate the effect of lateral sheet dimensions of pristine GO on the adsorption of $\mathrm{Ni}^{2+}$ in solution, as well as no studies joint between the size distribution and surface area of GO nanoparticles. We have investigated two sizes of GO nanoparticles (GO - $450 \mathrm{~nm}$ and GO - $200 \mathrm{~nm}$ ) at different time intervals, concentration, $\mathrm{pH}$ value, adsorbent dose and temperature.

\section{Materials and methods}

\section{Synthesis of graphite oxide}

As shown in Scheme 1 (ESI $\dagger$ ), graphite oxide was prepared by using the Hummer's method and conventionally by the oxidation-exfoliation reaction. ${ }^{32-34}$ Briefly, $1.0 \mathrm{~g}$ of graphite and $50 \mathrm{~g}$ $\mathrm{NaCl}$ were grounded in mortar for $20 \mathrm{~min}$, the ground graphite was dissolved in distilled water, filtrated, washed several times and dried in an oven at $40{ }^{\circ} \mathrm{C}$ for $6 \mathrm{~h}$. The filtrated graphite was stirred in $23 \mathrm{ml} \mathrm{95 \%} \mathrm{H}_{2} \mathrm{SO}_{4}$ overnight. The mixture was placed in an ice bath (below $10^{\circ} \mathrm{C}$ ) for starting the oxidation step, $3.0 \mathrm{~g}$
$\mathrm{KMnO}_{4}$ was added slowly over 3 hours with continuous stirring. Afterward, the mixture was heated up to $35^{\circ} \mathrm{C}$ for $30 \mathrm{~min}$ and to $50{ }^{\circ} \mathrm{C}$ for $45 \mathrm{~min}$ respectively. The mixture cooled down then $46 \mathrm{ml}$ of distilled water was slowly added to the solution, the solution temperature was increased to $98-105{ }^{\circ} \mathrm{C}$ with stirring for $45 \mathrm{~min}$. A $140 \mathrm{ml}$ distilled water and $10 \mathrm{ml}$ of $32 \% \mathrm{H}_{2} \mathrm{O}_{2}$ were added gradually to terminate the reaction. The final product was filtrated and washed 5 times with $5 \% \mathrm{HCl}$ and distilled water. Lastly, the graphite oxide was dried in an oven at $\left(50{ }^{\circ} \mathrm{C}\right)$ for $6 \mathrm{~h} .{ }^{34}$ The actual yield of GO is $1.46 \mathrm{~g}$.

\section{Synthesis of graphene oxide nanoparticles}

The graphene oxide nanoparticles were prepared according to our previous protocol. ${ }^{34}$ Shortly, $1.0 \mathrm{mg} \mathrm{ml}^{-1}$ of graphite oxide was sonicated in an ultra-sonication bath under controlled conditions (power, concentration and time), as shown in Scheme $1, \dagger$ step no. 3 (Size reduction).

\section{Preparation of different nickel(II) concentrations}

A $1000 \mathrm{mg} \mathrm{l}^{-1}$ stock solution of $\mathrm{NiSO}_{4} \cdot 6 \mathrm{H}_{2} \mathrm{O}$ was prepared by dissolving $0.4478 \mathrm{~g}$ in $100 \mathrm{ml}$ distilled water. The stock solution was used for the preparation of diluted solutions (200, 300, 400, 500, 600, 700, 800, and $900 \mathrm{ppm}$ ).

\section{Batch adsorption experiments}

Batch adsorption experiments were carried out in a water bath sonicator. The effect of adsorbent dose, contact time, initial concentration, $\mathrm{pH}$, and temperature were studied by using a UV-Vis spectrophotometer. Two sizes of GO particles (450 nm and $200 \mathrm{~nm}$ ) were used as an adsorbent to understand the crosstalk between different sizes of $\mathrm{GO}$ and $\mathrm{Ni}^{2+}$ adsorption. A $3.0 \mathrm{ml}$ nickel solution of different concentrations was shaken in closed bottles with $20 \mathrm{mg}$ GO as the desired adsorbent dose for various contact time (10-120 $\mathrm{min}$ ) and $\mathrm{pH}$ values from 2 to 10 . The separation of the solid phase from a solution was done by using suction filtration, and then the residual nickel amount in the filtrate was determined.

The surface area of GO nanoparticles was determined by using methylene blue (MB) experiment. ${ }^{35}$ A 100 ppm of methylene blue dye as stock solution was prepared in ultrahigh distilled water, different solutions of methylene blue were
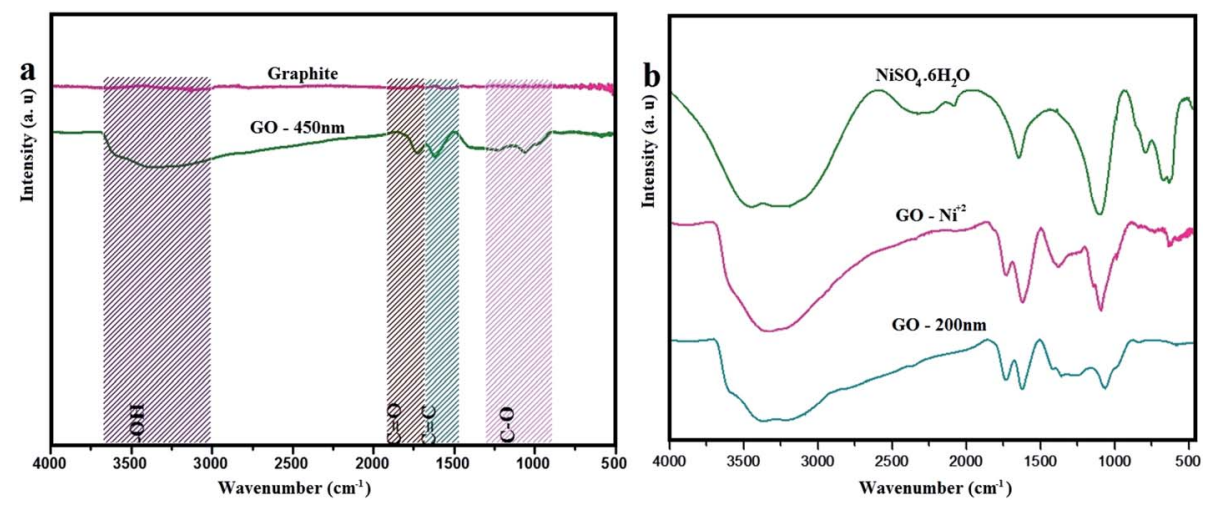

Fig. 1 FTIR spectra of (a) graphite and GO $-450 \mathrm{~nm}$. (b) $\mathrm{NiSO}_{4} \cdot 6 \mathrm{H}_{2} \mathrm{O}, \mathrm{GO}-\mathrm{Ni}^{2+}$ and $\mathrm{GO}-200 \mathrm{~nm}$. 
prepared for establishing the calibration curve. In separate experiments, $5 \mathrm{mg}$ of GO was mixed with $25 \mathrm{ml}$ of 16, 8, 4, 2 and $1 \mathrm{ppm}$ of $\mathrm{MB}$ for $10 \mathrm{~min}$ at $20{ }^{\circ} \mathrm{C}$ and $4000 \mathrm{rpm}$. The samples were filtrated and the concentration of $\mathrm{MB}$ at equilibrium was calculated.

\section{Result and discussion}

\section{Scanning electron microscopy (SEM)}

The scanning electron microscopy (SEM) is employed to study the morphology and the lateral sizes of GO nanoparticles. ${ }^{34,36} \mathrm{As}$ shown in Fig. 2, SEM exhibits two sizes of graphene oxide nanoparticles; as shown in panel (a) the average size (lateral width) of as-prepared GO particles is approximately $450 \mathrm{~nm}$. The average size of GO particles after sonication by using tip sonicator is approximately $200 \mathrm{~nm}$ as shown in panel (b). Fig. 2c represents the statistical analysis of GO particles deduced from SEM images. The SEM images were obtained using a FEI, NOVA NanoSEM-200 with an acceleration voltage of $15 \mathrm{kV}$.

\section{FTIR}

Fig. 1 exhibits the FTIR spectra of graphite and as prepared graphite oxide (GO $-450 \mathrm{~nm})$. The graphite spectrum shows no notable bands in the region of IR from $4000-500 \mathrm{~cm}^{-1}$. However GO reveals variation bands at 3312, 1730, 1612, 1231, $1077 \mathrm{~cm}^{-1}$ which corresponding to hydroxyl, carbonyl, $-\mathrm{C}=\mathrm{C}-$, epoxy, and C-O groups respectively. ${ }^{2}$ The broad band at $3312 \mathrm{~cm}^{-1}$ attributed to the stretching vibration of $(-\mathrm{OH})$ group, which is due to the hydroxyl group of carboxylic acid at the edges of GO sheets as well as the alcohol groups distributed on the basal plane of graphene oxide layers. The significant peak at $1612 \mathrm{~cm}^{-1}$ ascribed to $\mathrm{sp}^{2}$ aromatic pattern $(-\mathrm{C}=\mathrm{C}-)$, and the peak appeared at $1730 \mathrm{~cm}^{-1}$ is due to $(-\mathrm{C}=\mathrm{O})$ group. The weak band in the region of $1231 \mathrm{~cm}^{-1}$ is assigned to stretching vibration of epoxide group $(-\mathrm{C}-\mathrm{O})$, and the peak at $1077 \mathrm{~cm}^{-1}$ due to the alkoxy group $(-\mathrm{C}-\mathrm{O}) .{ }^{24,25}$ Fig. $1 \mathrm{~b}$ shows the FTIR spectra of free $\mathrm{Ni}^{2+}, \mathrm{GO}-\mathrm{Ni}^{2+}$, and $\mathrm{GO}-200 \mathrm{~nm}$. $\mathrm{Ni}^{2+}$ reveals a broad peak at $3200 \mathrm{~cm}^{-1}$, which assigned to symmetric stretching of the water molecule, moreover the bending vibration of water molecules observed at $1656 \mathrm{~cm}^{-1}$. The other peaks at $1096 \mathrm{~cm}^{-1}, 465 \mathrm{~cm}^{-1}, 632 \mathrm{~cm}^{-1}$, and $797 \mathrm{~cm}^{-1}$ are corresponding to fundamental vibrations of $\mathrm{SO}_{4}{ }^{2-}$ free ion namely as a non-degenerate, doubly degenerate, triply degenerate mode respectively. After adsorption of $\mathrm{Ni}^{2+}$, a broad band at $3312 \mathrm{~cm}^{-1}$ in GO was shifted to $3150 \mathrm{~cm}^{-1}$. The strong peak at $1730 \mathrm{~cm}^{-1}$ shifted to $1715 \mathrm{~cm}^{-1}$, which is assigned to $\mathrm{Ni}^{2+}$ adsorbed on GO particles. These findings are in agreement with previously reported data. ${ }^{37,38}$ The FTIR spectra were obtained using Bruker FTIR in the range between $4000-500 \mathrm{~cm}^{-1}$.

\section{UV-visible spectrophotometry}

The UV-visible Spectrophotometry (UV-Visible line 9100, photometric range: 320-1100 nm, Aqualabo company) was used in this study. Fig. 1a (ESI $\dagger$ ) reveals the UV visible spectroscopy of
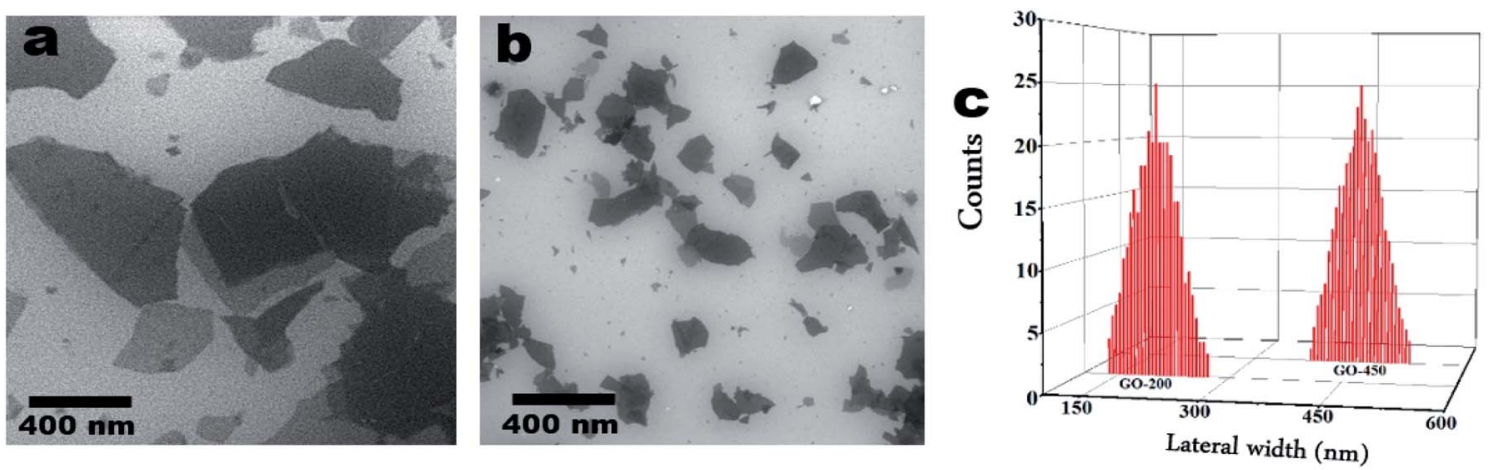

Fig. 2 SEM images of (a) GO - $450 \mathrm{~nm}$ and (b) $200 \mathrm{~nm}$. Panel (c) is the average width (nm) of GO particles deduced from SEM images.
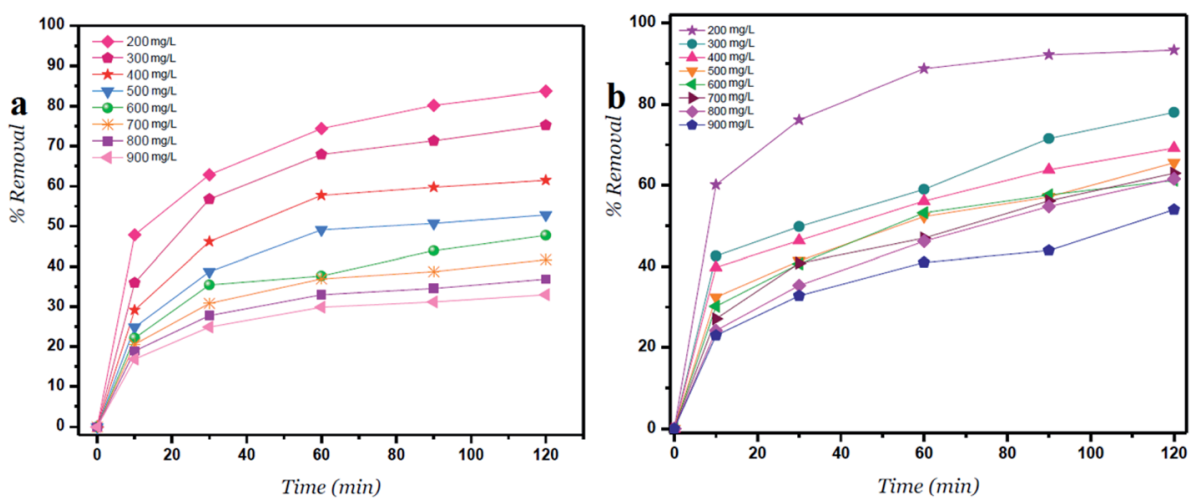

Fig. 3 Percent removal versus time for (a) GO $-450 \mathrm{~nm}$ and (b) GO - $200 \mathrm{~nm}$ at different concentrations. 
free $\mathrm{Ni}^{2+}$ ions at different concentrations. As the $\mathrm{Ni}^{2+}$ concentration increases the absorbance increases at different wavelengths (393 nm, $656 \mathrm{~nm}$, and $720 \mathrm{~nm})$. These wavelengths are assigned to $v_{1}={ }^{3} \mathrm{~A}_{2} \mathrm{~g}(\mathrm{~F}) \rightarrow{ }^{1} \mathrm{Eg}, v_{2}={ }^{3} \mathrm{~A}_{2} \mathrm{~g}(\mathrm{~F}) \rightarrow{ }^{3} \mathrm{~T}_{1} \mathrm{~g}(\mathrm{~F}), v_{3}=$ ${ }^{3} \mathrm{~A}_{2} \mathrm{~g}(\mathrm{~F}) \rightarrow{ }^{3} \mathrm{~T}_{1} \mathrm{~g}(\mathrm{P})$. The observed bands of $393 \mathrm{~nm}$ and $720 \mathrm{~nm}$ related to $v_{3}$ and $v_{2}$ respectively. While $v_{1}$ refers to $656 \mathrm{~nm} .^{39}$ Panel (b) reveals the calibration curve for determining the $\mathrm{Ni}^{2+}$ concentrations at equilibrium.

\section{Adsorption capacity}

The adsorption capacity $\left(\mathrm{mg} \mathrm{g}^{-1}\right)$ was estimated by using the following eqn (1):

$$
q_{\mathrm{e}}=\frac{\left(C_{\mathrm{i}}-C_{\mathrm{e}}\right) \mathrm{mg} \mathrm{L}^{-1}}{W_{\mathrm{g}}} \times V_{\mathrm{L}}
$$

where: $C_{\mathrm{i}}$ is the initial concentration of $\mathrm{Ni}^{2+}\left(\mathrm{mg} \mathrm{L}^{-1}\right), C_{\mathrm{e}}$ is the concentration at equilibrium $\left(\mathrm{mg} \mathrm{L}^{-1}\right), W_{\mathrm{g}}$ is the mass of $\mathrm{GO}(\mathrm{g})$, $V_{\mathrm{L}}$ is the volume of sample.

The adsorption capacity $\left(q_{\mathrm{e}}, \mathrm{mg} \mathrm{g}^{-1}\right)$ at different time intervals is increased with increasing the initial $\mathrm{Ni}^{2+}$ concentrations as shown in Fig. 4. Moreover, the lateral width of GO particles exhibits a major change in the adsorption capacity due to more surfaces of GO - $200 \mathrm{~nm}$ are available. As shown in Fig. 4a, the adsorption capacity of GO - $450 \mathrm{~nm}$ appeared as stabilized behavior above $400 \mathrm{mg} \mathrm{l}^{-1}$ of $\mathrm{Ni}^{2+}$ concentration. In panel $\mathrm{b}$, the GO - $200 \mathrm{~nm}$ exhibits a linear behavior with increasing $\mathrm{Ni}^{2+}$ concentration up to $900 \mathrm{mg} \mathrm{l}^{-1}$ after $60 \mathrm{~min}$ of incubation.

\section{Percent removal of $\mathrm{Ni}^{2+}$ at different concentrations and time intervals}

Fig. 3 shows the percent removal of $\mathrm{Ni}^{2+}$ ions, it depends on the lateral width of GO particles. As the size of GO decreases the percent removal increases due to high surface areas of GO $200 \mathrm{~nm}$. As shown in panel (a) the contact time reveals a minor change on the removal of $\mathrm{Ni}^{2+}$ after 60 min of incubation. In panel (b) the size of GO particles (GO - $200 \mathrm{~nm}$ ) shows higher removal of $\mathrm{Ni}^{2+}$ due to increasing adsorbate surfaces., ${ }^{\mathbf{1 , 2 4}}$

The removal of $\mathrm{Ni}^{2+}$ percent was calculated by using the following eqn (2):

$$
\% R=\frac{C_{\mathrm{i}}-C_{\mathrm{e}}}{C_{\mathrm{i}}} \times 100
$$

where: $C_{\mathrm{i}}\left(\mathrm{mg} \mathrm{l}^{-1}\right)$ is the initial concentration of $\mathrm{Ni}^{2+}, C_{\mathrm{e}}\left(\mathrm{mg} \mathrm{l}^{-1}\right)$ is the concentration at equilibrium deduced from the calibration curve. ${ }^{40}$

\section{Percent removal of $\mathrm{Ni}^{2+}$ at different $\mathrm{pH}$}

The percentage removal of $\mathrm{Ni}^{2+}$ at different $\mathrm{pH}$ values from 2 to 10 is shown in Fig. 5, this figure shows that the $\mathrm{Ni}^{2+}$ uptake was increased between 2 and $6 \mathrm{pH}$ values. This indicates that the competitive adsorption between $\mathrm{Ni}^{2+}$ ions and $\mathrm{H}_{3} \mathrm{O}^{+}$ions on the surface of GO. At a pH higher than 6, the negative charge on the surface of GO particles increases and lead to strong electrostatic interaction between $\mathrm{Ni}^{2+}$ and $\mathrm{GO}$ particles under alkaline condition. ${ }^{18,24}$ On the other hand, $\mathrm{Ni}^{2+}$ ions can present as $\left(\mathrm{Ni}(\mathrm{OH})^{+}, \mathrm{Ni}(\mathrm{OH})_{2}, \mathrm{Ni}(\mathrm{OH})_{3}{ }^{-}, \mathrm{Ni}(\mathrm{OH})_{4}{ }^{2-}\right)$ and may be precipitated onto the surface of GO particles., ${ }^{1,38}$

The lateral sheet dimension (GO - $200 \mathrm{~nm}$ ) shows higher removal comparing with GO - $450 \mathrm{~nm}$. This behavior is attributed to more surfaces of GO particles. In conclusion, the

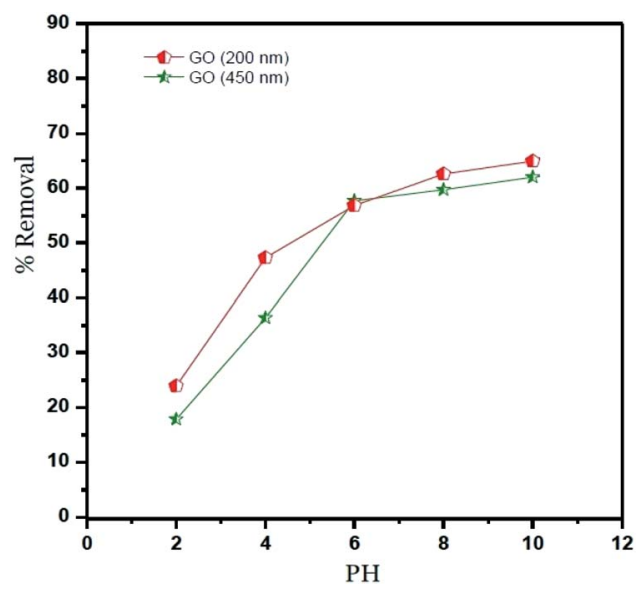

Fig. 5 Percent removal of $\mathrm{Ni}^{2+}$ at different $\mathrm{pH}$ values. $\mathrm{Ni}^{2+}=400 \mathrm{mg}$ $\mathrm{I}^{-1}, T=25^{\circ} \mathrm{C}$
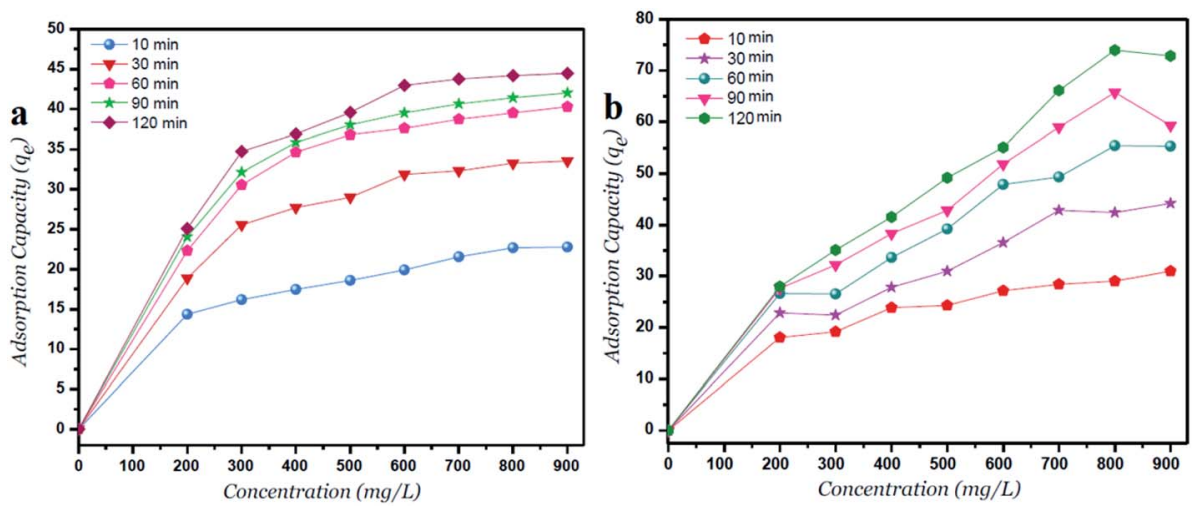

Fig. 4 Adsorption capacity versus $\mathrm{Ni}^{2+}$ concentrations for (a) GO - $450 \mathrm{~nm}$ and (b) GO - $200 \mathrm{~nm}$ at different time intervals. 


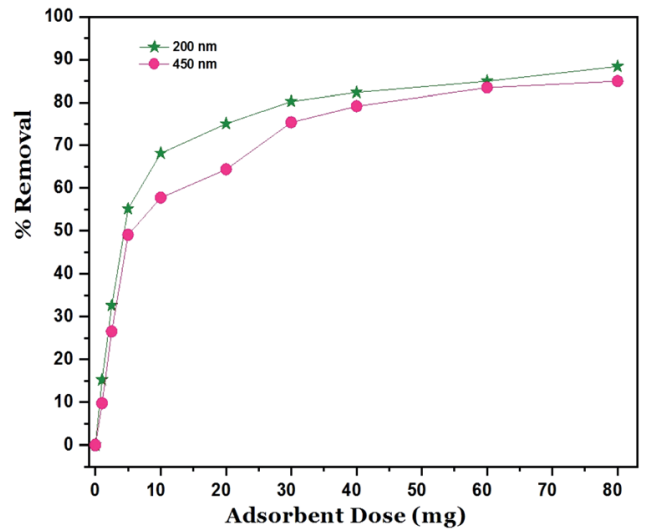

Fig. 6 Effect of adsorbent dose $\left(\mathrm{Ni}^{2+}=400 \mathrm{mg} \mathrm{l}^{-1}, T=25^{\circ} \mathrm{C}, \mathrm{pH}=6\right)$.

optimum $\mathrm{pH}$ value of $\mathrm{Ni}^{2+}$ adsorbed onto $\mathrm{GO}-450$ and $\mathrm{GO}-$ $200 \mathrm{~nm}$ is 6 , which was used for further studies.

\section{Adsorbent dose}

The effect of adsorbent dose on $\mathrm{Ni}^{2+}$ removals is shown in Fig. 6 . The amount of GO varying from 1.0 to $80 \mathrm{mg}$ and the initial $\mathrm{Ni}^{2+}$ concentration for adsorbent dose was fixed at $400 \mathrm{mg} \mathrm{l}^{-1}$. The results reveal that the removal of $\mathrm{Ni}^{2+}$ by using $\mathrm{GO}-450 \mathrm{~nm}$ and GO - $200 \mathrm{~nm}$ increased with an increasing of adsorption dose from $1.0 \mathrm{mg}$ to $20 \mathrm{mg}$, this behaviour is attributed to the increasing of the availability of surfaces at a higher amount of adsorbents. A plateau was reached from 20 up to $80 \mathrm{mg}$ of adsorbent, and this may be imputed to overcrowding in the adsorbed molecules. ${ }^{1}$

\section{Adsorption isotherm models}

The adsorption isotherm plays a key role for the analysis of adsorption process that elucidates how the $\mathrm{Ni}^{2+}$ ions distribute between the solid-liquid interface once the system is at equilibrium. The most model used is Langmuir isotherm for monolayer adsorption onto the adsorbent particles. It can be expressed as eqn (3).

$$
\frac{C_{\mathrm{e}}}{q_{\mathrm{e}}}=\frac{C_{\mathrm{e}}}{q_{\max }}+\frac{1}{K_{\mathrm{L}} q_{\max }}
$$

where: $q_{\mathrm{e}}$ is the amount of $\mathrm{Ni}^{2+}$ ions adsorbed per unit weight of adsorbent $\left(\mathrm{mg} \mathrm{g}^{-1}\right), C_{\mathrm{e}}$ is the $\mathrm{Ni}^{2+}$ concentration at equilibrium $\left(\mathrm{mg} \mathrm{l}^{-1}\right) . q_{\max }$ is the maximum sorption capacity specified by the reactive species in an ideal monolayer system $\left(\mathrm{mg} \mathrm{g}^{-1}\right) . K_{\mathrm{L}}$ is the Langmuir constant affined to a free energy of adsorption (l $\left.\mathrm{mg}^{-1}\right)$.

The Langmuir parameter $\left(R_{\mathrm{L}}\right)$ is a dimensionless constant separation factor defined as in eqn (4)

$$
R_{\mathrm{L}}=\frac{1}{1+K_{\mathrm{L}} C_{\mathrm{i}}}
$$

where: $C_{\mathrm{i}}$ is the maximum initial concentration of adsorbate $\left(\mathrm{mg} \mathrm{l}^{-1}\right), K_{\mathrm{L}}$ is the Langmuir constant $\left(\mathrm{L} \mathrm{mg}^{-1}\right) . R_{\mathrm{L}}$ value indicates the adsorption reliable if $R_{\mathrm{L}}>1$ unfavorable, $0<R_{\mathrm{L}}<1$ favorable, $R_{\mathrm{L}}=1$ for linear adsorption, and $R_{\mathrm{L}}=0$ for irreversible adsorption. ${ }^{1}$

The Freundlich model is an empirical equation consider that adsorption of metal ions occurs on heterogeneous surface by multilayer adsorption; the linear form of Freundlich can be expressed in eqn (5).

$$
\ln q_{\mathrm{e}}=\ln K_{\mathrm{f}}+\frac{1}{n} \ln C_{\mathrm{e}}
$$

where: $K_{\mathrm{f}}$ and $(n)$ are the Freundlich parameters related to adsorption capacity and adsorption intensity respectively. ${ }^{\mathbf{4 1}}$

\section{Langmuir and Freundlich isotherm models using GO - 450 nm}

A plot of $C_{\mathrm{e}} / q_{\mathrm{e}}$ versus $C_{\mathrm{e}}$ at different time intervals gives a linear relation with the slop of $1 / q_{\max }$ and intercept of $1 /\left(K_{\mathrm{L} .} q_{\max }\right)$ as shown in Fig. 7a. The Langmuir model postulates that the uptake of $\mathrm{Ni}^{2+}$ ions occurs on a homogenous surface by monolayer adsorption without interaction between the adsorbed ions. For data collection at equilibrium, initial metal concentrations were varied while the GO adsorbent mass remained constant. The adsorption parameters of the Langmuir isotherm model are shown in Table 1 (ESI $\dagger$ ) at different time intervals. The correlation coefficient of Langmuir isotherm $\left(R^{2}\right)$ was approximately 0.999 , which reveals a high correlation or linear relationship. Therefore the adsorption of $\mathrm{Ni}^{2+}$ onto $\mathrm{GO}-$ $450 \mathrm{~nm}$ is correlated well with the Langmuir equation.
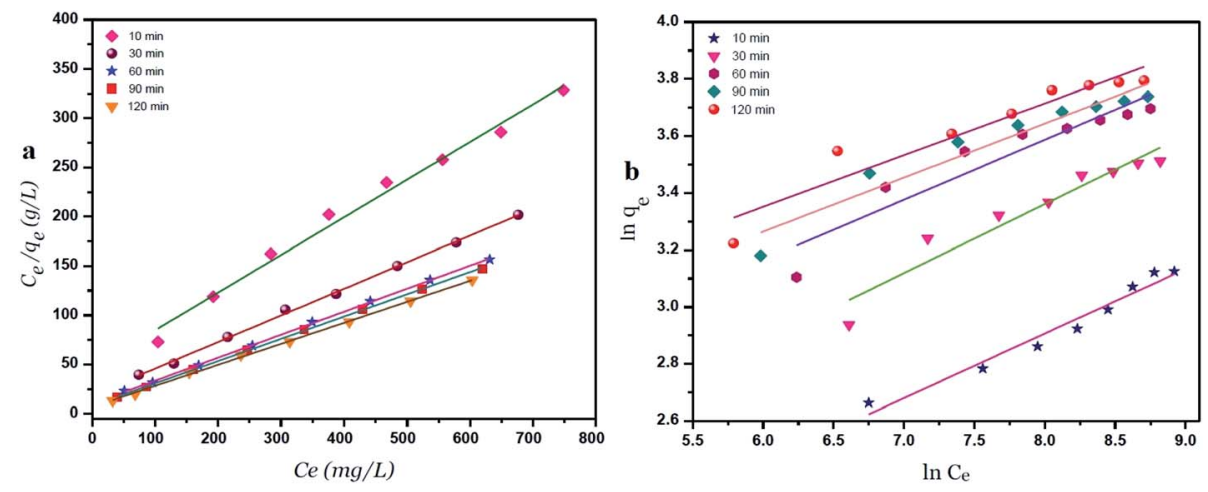

Fig. 7 Langmuir (a) and Freundlich (b) adsorption isotherm of $\mathrm{Ni}^{2+}$ onto $\mathrm{GO}-450 \mathrm{~nm}$ at $25^{\circ} \mathrm{C}$. 

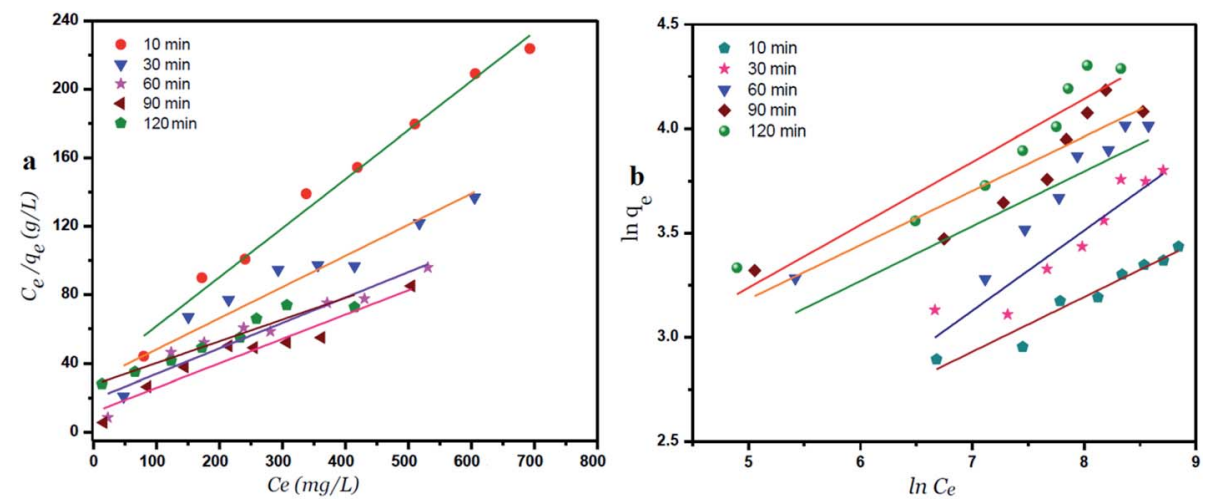

Fig. 8 Langmuir (a) and Freundlich (b) adsorption isotherm of $\mathrm{Ni}^{2+}$ onto $\mathrm{GO}-200 \mathrm{~nm}$ at $25^{\circ} \mathrm{C}$.

The Freundlich isotherm model interpreted as sorption to heterogeneous surfaces as shown in Fig. 7b. The Freundlich constant $n$ between 1 and 10 provides favourable adsorption tends. The larger value of $n$ means stronger interaction between the $\mathrm{Ni}^{2+}$ ions and GO nanoparticles as shown in Table 1 (ESI $\dagger$ ). The Freundlich isotherm parameter $\left(K_{\mathrm{F}}\right)$ was calculated according to eqn (5), the value increases as the time interval increased which indicates the Freundlich model fitted well with the experimental data. The correlation coefficient of Freundlich isotherm $\left(R^{2}\right)$ was approximately 0.910 .

\section{Langmuir and Freundlich isotherm models using GO - 200 nm}

Fig. 8 exhibits the Langmuir and Freundlich adsorption isotherm of $\mathrm{Ni}^{2+}$ onto $\mathrm{GO}-200 \mathrm{~nm}$ at $25^{\circ} \mathrm{C}$. Panel (a) shows the linear relation between $C_{\mathrm{e}} / q_{\mathrm{e}}$ versus $\mathrm{Ni}^{2+}$ concentrations at equilibrium for different time intervals. The values of $K_{\mathrm{L}}$ and $q_{\mathrm{m}}$ calculated from the plotted data (slope and intercept) are reported in Table 2 (ESI $\dagger$ ). The value of $q_{\mathrm{m}}$ of $\mathrm{Ni}^{2+}$ onto GO $200 \mathrm{~nm}$ is higher than that onto GO $-450 \mathrm{~nm}$. This result indicated that a complete and uniform monolayer of $\mathrm{Ni}^{2+}$ covering the surfaces of GO particles over the whole concentrations. However the $R^{2}$ values at different time intervals were less than that onto GO $-450 \mathrm{~nm}$, indicating that the size of GO $200 \mathrm{~nm}$ particles affect $\mathrm{Ni}^{2+}$ uptake onto the adsorbent.
Langmuir model indicated the best fitting $\left(R^{2}=0.999\right)$ to the isotherm data is with $\mathrm{GO}-450 \mathrm{~nm}$ size distributions.

In panel (b), the same linear relation appeared between $\ln q_{\mathrm{e}}$ versus $\ln C_{\mathrm{e}}$ for Freundlich isotherm. The value of $n$ is higher than 1 indicated that the adsorption capacity was slightly restrained at lower equilibrium concentration. As shown in Table 2 (ESI $\dagger$ ), the values of $n$ are studied as an indication of the linearity deviation, as well as it is used to predict the heterogeneity degree of the adsorbent. Moreover the value of $n$ is considered as an indication whether the adsorption process is favorable or not. The value of $n$ corresponding to GO $-450 \mathrm{~nm}$ is greater than that with $\mathrm{GO}-200 \mathrm{~nm}$, illustrating that a stronger capacity of $\mathrm{Ni}^{2+}$ onto $\mathrm{GO}-450 \mathrm{~nm}$. The Freundlich constant $K_{\mathrm{F}}$ has been found as a relative measure of adsorption capacity. As the value of $K_{\mathrm{F}}$ increases the adsorption capacity increases. The reported values of $K_{\mathrm{F}}$ by using $\mathrm{GO}-450 \mathrm{~nm}$ as adsorbent were greater than that using GO $-200 \mathrm{~nm}$. This result summarizing that the uptake of $\mathrm{Ni}^{2+}$ ions with high adsorptive capacity of adsorbent.

In this work, the data of $\mathrm{Ni}^{2+}$ onto $\mathrm{GO}-450 \mathrm{~nm}$ and $\mathrm{GO}-$ $200 \mathrm{~nm}$ of equilibrium adsorption was better fitted to Langmuir than Freundlich adsorption isotherm model. The maximum adsorption capacities of monolayer were $43.478 \mathrm{mg} \mathrm{g}^{-1}$ and $66.667 \mathrm{mg} \mathrm{g}^{-1}$ for GO $-450 \mathrm{~nm}$ and GO $-200 \mathrm{~nm}$ respectively as shown in Fig. 9.

The isotherm parameters are summarized in Table 1.
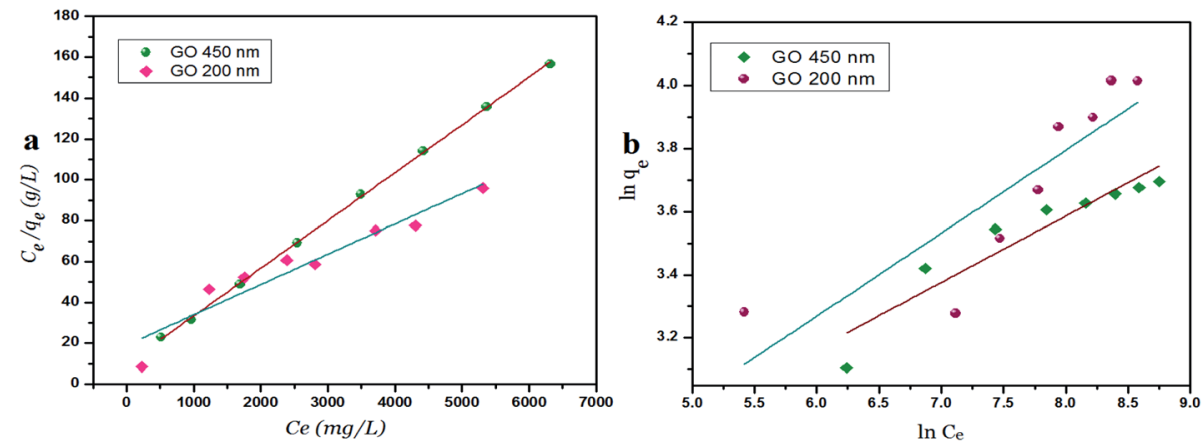

Fig. 9 Langmuir (a) and Freundlich (b) adsorption isotherm of $\mathrm{Ni}^{2+}$ onto $450 \mathrm{~nm}$ and $200 \mathrm{~nm}$ at 60 min of incubation. 
Table 1 Langmuir and Freundlich isotherm parameters

\begin{tabular}{lllllll}
\hline & \multicolumn{2}{l}{ Langmuir } & & & \multicolumn{2}{l}{ Freundlich } \\
\cline { 2 - 3 } Adsorbents & $q_{\mathrm{m}}$ & $k_{1}$ & $R_{\mathrm{L}}$ & & $n$ & $K_{\mathrm{f}}$ \\
\hline GO $450 \mathrm{~nm}$ & 43.478 & 0.0023 & 0.046 & & 4.762 & 6.686 \\
GO $200 \mathrm{~nm}$ & 66.667 & 0.0008 & 0.124 & & 3.802 & 5.419
\end{tabular}
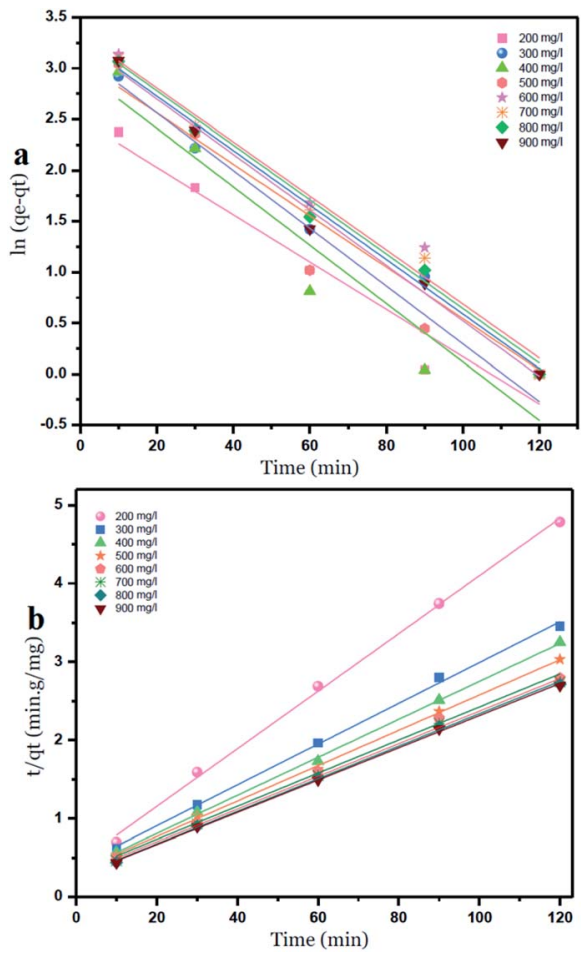

Fig. 10 Pseudo first order (a) and Pseudo second order kinetic adsorption model of $\mathrm{Ni}^{2+}$ onto $\mathrm{GO}-450 \mathrm{~nm}$ at $25^{\circ} \mathrm{C}$.

\section{Kinetic study}

Two kinetic models were used to investigate the adsorption of $\mathrm{Ni}^{2+}$ ions onto GO particles. The models were considered as follows:
Lagergren's pseudo-first-order model which can be expressed by eqn (6):

$$
\ln q_{\mathrm{e}}-q_{\mathrm{t}}=\ln q_{\mathrm{e}}-k_{1} t
$$

where: $q_{\mathrm{e}}$ is the adsorption capacity at equilibrium $\left(\mathrm{mg} \mathrm{g}^{-1}\right), q_{t}$ is the adsorption capacity at any time $t(\mathrm{~min}) . k_{1}$ is the first-order rate constant adsorption $\min ^{-1}$. Values of $q_{\mathrm{e}}$ and $k_{1}$ were calculated by plotting of $\ln q_{\mathrm{e}}-q_{t}$ versus time.

Ho's pseudo-second-order model is given by eqn (7):

$$
\frac{t}{q_{t}}=\frac{t}{q_{\mathrm{e}}}+\frac{1}{k_{2} q_{\mathrm{e}}^{2}}
$$

where: $k_{2}$ is the rate constant for the pseudo-second-order adsorption $\left(\mathrm{g} \mathrm{mg} \mathrm{min}^{-1}\right.$ ), values of $k_{2}$ and $q_{\mathrm{e}}$ for different initial concentrations of ions were calculated from the intercept and slope respectively. ${ }^{42}$

The intercepts and slope of the linear plots for the adsorption of nickel by GO - $450 \mathrm{~nm}$ and GO - $200 \mathrm{~nm}$ were used to calculate the kinetic parameters, as shown in Fig. 10 and 11, the kinetic constant values are summarized in Table 6 (ESI†).

\section{Effect of temperature}

The adsorption of $\mathrm{Ni}^{2+}$ ions was studied at different temperatures $\left(25^{\circ} \mathrm{C}, 45^{\circ} \mathrm{C}\right.$, and $\left.65^{\circ} \mathrm{C}\right)$, the adsorption data were carried out with $400 \mathrm{mg} \mathrm{l}^{-1}$ of $\mathrm{Ni}^{2+}$ at $\mathrm{pH}=6$.

The parameters of thermodynamic like entropy $\Delta S^{\circ}$, enthalpy $\Delta H$, and Gibbs free energy $\Delta G$ can be expressed by Van't Hoff equation

$$
\ln \left(\frac{q_{\mathrm{e}}}{c_{\mathrm{e}}}\right)=\frac{\Delta S^{\circ}}{R}-\frac{\Delta H^{\circ}}{R \cdot T}
$$

where: $T(\mathrm{~K})$ is the solution temperature. $R$ is the gas constant (8.314 $\mathrm{J} \mathrm{mol}^{-1} \mathrm{~K}^{-1}$ )

From the plotting of $\ln \left(q_{\mathrm{e}} / \mathrm{C}_{\mathrm{e}}\right)$ versus $(1 / T)$ entropy $\left(\Delta S^{\circ}\right)$ and enthalpy $\left(\Delta H^{\circ}\right)$ were calculated by using the intercept and slope respectively as shown in Fig. 12, and the Gibbs free energy was calculated by using this eqn (8). ${ }^{\mathbf{1 8 , 4 3}}$

As shown in Table 9 (ESI $\dagger$ ), the calculated values of the thermodynamic parameters are elucidated. The positive values of $\Delta H^{\circ}$ indicate that the adsorption process of $\mathrm{Ni}^{2+}$ onto $\mathrm{GO}-$ $450 \mathrm{~nm}$ and $200 \mathrm{~nm}$ is an endothermic process while the
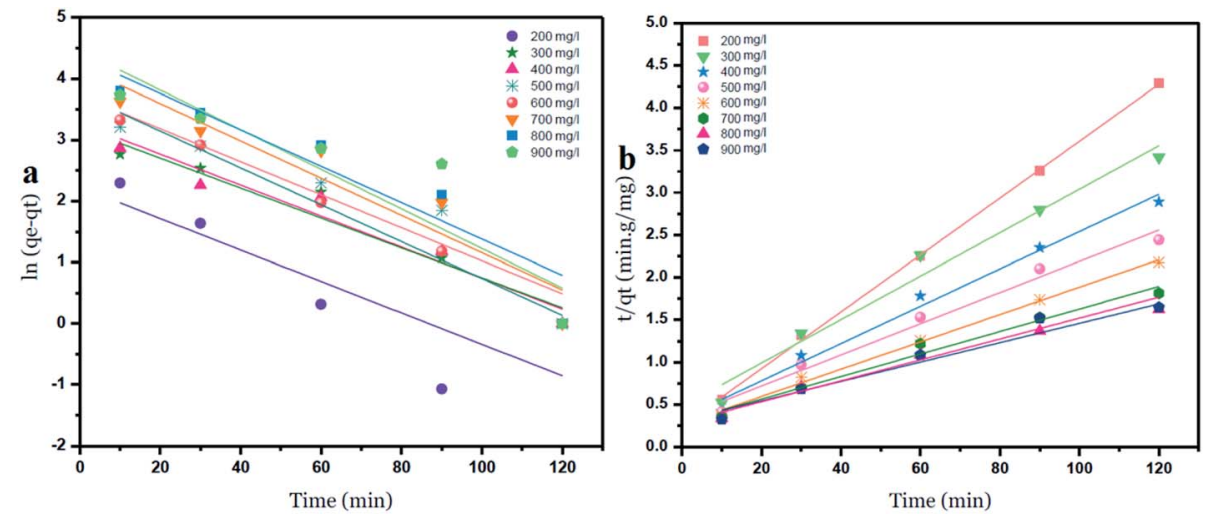

Fig. 11 Pseudo first order (a) and Pseudo second order (b) kinetic adsorption model of $\mathrm{Ni}^{2+}$ onto GO $-200 \mathrm{~nm}$ at $25^{\circ} \mathrm{C}$. 


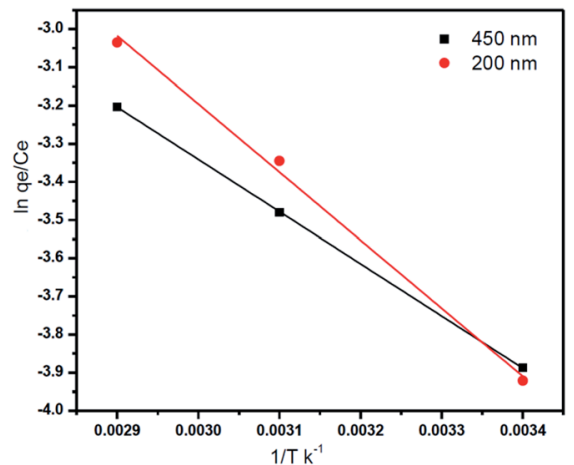

Fig. 12 Vant Hoff for the adsorption of $\mathrm{Ni}^{2+}$ onto $\mathrm{GO}-450 \mathrm{~nm}$ and $\mathrm{GO}-200 \mathrm{~nm} .\left(\mathrm{Ni}^{2+}=400 \mathrm{mg} \mathrm{l}{ }^{-1}\right)$.

positive values of $\Delta S^{\circ}$ indicate that increased the randomness at the solid/liquid interface during the adsorption process. The negative values of $\Delta G^{\circ}$ suggest that the adsorption of $\mathrm{Ni}^{2+}$ onto $\mathrm{GO}-450 \mathrm{~nm}$ and $200 \mathrm{~nm}$ is a spontaneous process but as these values are in the range between -20 and $0 \mathrm{~kJ} \mathrm{~mol}^{-1}$ the process is classified physisorption. ${ }^{\mathbf{1 , 1 8}}$

\section{Surface area measurements of GO materials}

The specific surface area of graphene oxide $(450 \mathrm{~nm}, 200 \mathrm{~nm})$ was calculated by the following equation:

$$
S=\frac{q_{\mathrm{m}} \times a_{\mathrm{MB}} \times N_{\mathrm{A}} \times 10^{-20}}{M}
$$

where: $S$ is the specific surface area in $\mathrm{m}^{2} \mathrm{~g}^{-1} ; q_{\mathrm{m}}$ is the maximum adsorption capacity of methylene blue at the monolayer of GO in $\mathrm{mg} \mathrm{g}^{-1}, a_{\mathrm{MB}}$ is the occupied surface area of one molecule of methylene blue $=130 \AA^{2}, N_{\mathrm{A}}$ represents Avogadro's number; and $M$ is the molecular weight of methylene blue, $373.9 \mathrm{~g} \mathrm{~mol}^{-1}$. The maximum adsorption capacity $\left(q_{\mathrm{m}}\right)$ of GO 450 and $\mathrm{GO}-200 \mathrm{~nm}$ is 357.1 and $502.5 \mathrm{mg} \mathrm{g}^{-1}$ respectively which was evaluated from eqn (3).

\section{Conclusion}

The removal of heavy metal ions from aqueous solution can be achieved by using graphene oxide particles at different size distributions (GO - $450 \mathrm{~nm}$ and GO - $200 \mathrm{~nm}$ ). The smaller size of GO particles provided better removal due to high surface to volume ratio, as well as various oxygen groups like hydroxyl, epoxy and carboxyl present after oxidation and ultrasonication. The adsorption capacity of GO - $450 \mathrm{~nm}$ appeared as stabilized behavior above $400 \mathrm{mg} \mathrm{l}^{-1} \mathrm{Ni}^{2+}$ concentration. However the GO - $200 \mathrm{~nm}$ exhibits a linear behavior with increasing $\mathrm{Ni}^{2+}$ concentration upto $900 \mathrm{mg} \mathrm{l}^{-1}$ after $60 \mathrm{~min}$ of incubation. This research demonstrates that GO particles can be an effective adsorbent for toxic metal removal depending on the particle's size distribution.

\section{Fund}

Support fund for Palestinian Universities (Jordan University).

\section{Conflicts of interest}

The authors declare that no competing interests.

\section{Acknowledgements}

The authors thank the IFW Institute, Dresden, Germany.

\section{References}

1 W. Konicki, M. Aleksandrzak and E. Mijowska, Equilibrium and kinetics studies for the adsorption of $\mathrm{Ni2}+$ and $\mathrm{Fe} 3+$ ions from aqueous solution by graphene oxide, Pol. J. Chem. Technol., 2017, 19(3), 120-129.

2 R. L. White, C. M. White, H. Turgut, A. Massoud and Z. R. Tian, Comparative studies on copper adsorption by graphene oxide and functionalized graphene oxide nanoparticles, J. Taiwan Inst. Chem. Eng., 2018, 85, 18-28.

3 P. Tan, Y. $\mathrm{Hu}$ and Q. Bi, Competitive adsorption of $\mathrm{Cu} 2+$, $\mathrm{Cd} 2+$ and $\mathrm{Ni2}+$ from an aqueous solution on graphene oxide membranes, Colloids Surf., A, 2016, 509, 56-64.

4 J. Lee, H.-R. Chae, Y. J. Won, K. Lee, C.-H. Lee, H. H. Lee, et al., Graphene oxide nanoplatelets composite membrane with hydrophilic and antifouling properties for wastewater treatment, J. Memb. Sci., 2013, 448, 223-230, available from: http://linkinghub.elsevier.com/retrieve/pii/ S0376738813006637.

5 D. R. Dreyer, S. Park, C. W. Bielawski and R. S. Ruoff, The Chemistry of Graphene Oxide, Chem. Soc. Rev., 2010, 39(1), 228-240, available from: http:/www.ncbi.nlm.nih.gov/ pubmed/20023850.

6 H.-W. Liu, S.-H. Hu, Y.-W. Chen and S.-Y. Chen, Characterization and drug release behavior of highly responsive chip-like electrically modulated reduced graphene oxide-poly(vinyl alcohol) membranes, J. Mater. Chem., 2012, 22(33), 17311.

7 C.-H. Lu, H.-H. Yang, C.-L. Zhu, X. Chen and G.-N. Chen, A graphene platform for sensing biomolecules, Angew. Chem., Int. Ed., 2009, 48(26), 4785-4787, available from: http:// www.ncbi.nlm.nih.gov/pubmed/19475600.

8 H. Yue, W. Wei, Z. Yue, B. Wang, N. Luo, Y. Gao, et al., The Role of The Lateral Dimension of Graphene Oxide in The Regulation of Cellular Responses, Biomaterials, 2012, 33(16), 4013-4021, available from: http:// www.ncbi.nlm.nih.gov/pubmed/22381473.

9 S. D. Kim, W. L. Zhang and H. J. Choi, Pickering emulsionfabricated polystyrene-graphene oxide microspheres and their electrorheology, J. Mater. Chem. C, 2014, 2, 7541, available from: http://xlink.rsc.org/?DOI=C4TC01040J.

10 S. Gilje, S. Han, M. Wang, K. L. Wang and R. B. Kaner, A chemical route to graphene for device applications, Nano Lett., 2007, 7(11), 3394-3398, available from: http:// www.ncbi.nlm.nih.gov/pubmed/17944523.

11 B. Tian, C. Wang, S. Zhang, L. Feng and Z. Liu, Photothermally enhanced photodynamic therapy delivered by nano-graphene oxide, ACS Nano, 2011, 5(9), 7000-7009. 
12 Y. Liu, D. Yu, C. Zeng, Z. Miao and L. Dai, Biocompatible graphene oxide-based glucose biosensors, Langmuir, 2010, 26(9), 6158-6160, available from: http:// www.ncbi.nlm.nih.gov/pubmed/20349968.

13 S. Chowdhury and R. Balasubramanian, Recent advances in the use of graphene-family nanoadsorbents for removal of toxic pollutants from wastewater, Adv. Colloid Interface Sci., 2014, 204, 35-56, available from: http:// www.ncbi.nlm.nih.gov/pubmed/24412086.

14 Y. Wang, Z. Li, J. Wang, J. Li and Y. Lin, Graphene and graphene oxide: biofunctionalization and applications in biotechnology, Trends Biotechnol., 2011, 29(5), 205-212, available from: http://www.ncbi.nlm.nih.gov/pubmed/ 21397350.

15 A. Magrez, S. Kasas, V. Salicio, N. Pasquier, J. W. Seo, M. Celio, et al., Cellular toxicity of carbon-based nanomaterials, Nano Lett., 2006, 6(6), 1121-1125, available from: http:/www.ncbi.nlm.nih.gov/pubmed/16771565.

16 Y. Chang, S.-T. Yang, J.-H. Liu, E. Dong, Y. Wang, A. Cao, et al., In Vitro Toxicity Evaluation of Graphene Oxide on A549 Cells, Toxicol. Lett., 2011, 200(3), 201-210, available from: http:/www.ncbi.nlm.nih.gov/pubmed/21130147.

17 E. L. K. Chng and M. Pumera, The Toxicity of Graphene Oxides: Dependence on the Oxidative Methods Used, Chem. - Eur. J., 2013, 19(25), 8227-8235, available from: http://www.ncbi.nlm.nih.gov/pubmed/23630053.

18 S. M. Sallam, A. El-saharty and A. Ahmed, Adsorption of Toxic Ni ( II ) from an Aqueous Solution by Bentonite, Int. J. Ecotoxicol. Ecobiol., 2017, 2(4), 158-165.

19 V. K. Gupta, Suhas, A. Nayak, S. Agarwal, M. Chaudhary and I. Tyagi, Removal of Ni (II) ions from water using scrap tire, $J$. Mol. Liq., 2014, 190, 215-222.

20 X. Weng, J. Wu, L. Ma, G. Owens and Z. Chen, Impact of synthesis conditions on $\mathrm{Pb}(\mathrm{II})$ removal efficiency from aqueous solution by green tea extract reduced graphene oxide, Chem. Eng. J., 2019, 359, 976-981.

21 S. Sheshmani, M. Akhundi Nematzadeh, S. Shokrollahzadeh and A. Ashori, Preparation of graphene oxide/chitosan/ $\mathrm{FeOOH}$ nanocomposite for the removal of $\mathrm{Pb}(\mathrm{II})$ from aqueous solution, Int. J. Biol. Macromol., 2015, 80, 475-480, DOI: 10.1016/j.ijbiomac.2015.07.009.

$22 \mathrm{~W}$. Fu and Z. Huang, Magnetic dithiocarbamate functionalized reduced graphene oxide for the removal of $\mathrm{Cu}(\mathrm{II}), \mathrm{Cd}(\mathrm{II}), \mathrm{Pb}(\mathrm{II})$, and $\mathrm{Hg}$ (II) ions from aqueous solution: Synthesis, adsorption, and regeneration, Chemosphere, 2018, 209, 449-456.

23 L. El Fakir, M. Flayou, A. Dahchour, S. Sebbahi, F. KifaniSahban and S. El Hajjaji, Adsorptive removal of copper (II) from aqueous solutions on phosphates: equilibrium, kinetics, and thermodynamics, Desalin. Water Treat., 2016, 57(36), 17118-17127.

24 L. P. Lingamdinne, J. R. Koduru, H. Roh, Y. L. Choi, Y. Y. Chang and J. K. Yang, Adsorption removal of $\mathrm{Co}(\mathrm{II})$ from waste-water using graphene oxide, Hydrometallurgy, 2016, 165, 90-96.
25 M. Rao, A. V. Parwate and A. G. Bhole, Removal of Cr6+ and $\mathrm{Ni} 2+$ from aqueous solution using bagasse and fly ash, Waste Manag., 2002, 22(7), 821-830.

26 A. R. Shetty, Metal Anion Removal from Wastewater Using Chitosan in a Polymer Enhanced Diafiltration System, Worcester Polytechnic Institute, 2006.

27 M. Wang, Z. Wang, X. Zhou and S. Li, Efficient removal of heavy metal ions in wastewater by using a novel alginateEDTA hybrid aerogel, Appl. Sci., 2019, 9(3), 1-14.

28 Q. Huang, L. Chai, X. Wang, Y. L. Wu, Q. Li, Y. Hu and J. Qian, Co/N-doped carbon nanosheets derived from InOF1 precursors for efficient Zn-Air battery, Microporous Mesoporous Mater., 2021, 314, 110868.

29 X. Wang, Z. Zhu, L. Chai, J. Ding, L. Zhong, A. Dong, et al., Generally transform 3-dimensional In-based metal-organic frameworks into 2-dimensional Co,N-doped carbon nanosheets for Zn-air battery, J. Power Sources, 2019, 440, 227158, DOI: 10.1016/j.jpowsour.2019.227158.

30 Q. Huang, Y. Guo, X. Wang, L. Chai, J. Ding, L. Zhong, et al., In-MOF-derived ultrathin heteroatom-doped carbon nanosheets for improving oxygen reduction, Nanoscale, 2020, 12(18), 10019-10025.

31 T. C. Ho, Determination of Pb(II), Cu(II) and Ni(II) in Water Direct Measurement Using UV/Vis Spectrophotometer, Universiti Sains Malaysia, 2015.

32 N. I. Zaaba, K. L. Foo, U. Hashim, S. J. Tan, W. W. Liu and C. H. Voon, Synthesis of Graphene Oxide using Modified Hummers Method: Solvent Influence, Procedia Eng., 2017, 184, 469-477, DOI: 10.1016/j.proeng.2017.04.118.

33 G. Zhao, X. Ren, X. Gao, X. Tan, J. Li, C. Chen, et al., Removal of $\mathrm{Pb}$ (ii) ions from aqueous solutions on few-layered graphene oxide nanosheets, Dalton Trans., 2011, 40(41), 10945-10952.

34 S. Makharza, G. Cirillo, A. Bachmatiuk, O. Vittorio, R. G. Mendes, S. Oswald, et al., Size-Dependent Nanographene Oxide as a Platform for Efficient Carboplatin Release, J. Mater. Chem. B, 2013, 1(44), 61076114, available from: http://xlink.rsc.org/?DOI=c3tb21090a.

35 L. Chen, C. Batchelor-McAuley, B. Rasche, C. Johnston, N. Hindle and R. G. Compton, Surface area measurements of graphene and graphene oxide samples: Dopamine adsorption as a complement or alternative to methylene blue?, Appl Mater Today, 2020, 18, 100506, DOI: 10.1016/ j.apmt.2019.100506.

36 O. Vittorio, M. Le Grand, S. A. Makharza, M. Curcio, P. Tucci, F. Iemma, et al., Doxorubicin synergism and resistance reversal in human neuroblastoma $\mathrm{BE}(2) \mathrm{C}$ cell lines: An in vitro study with dextran-catechin nanohybrids, Eur. J. Pharm. Biopharm., 2018, 122, 176-185, DOI: 10.1016/ j.ejpb.2017.11.005.

37 P. Kathiravan, T. Balakrishnan, C. Srinath, K. Ramamurthi and S. Thamotharan, Growth and characterization of $\alpha$ nickel sulphate hexahydrate single crystal, Karbala Int. J. Mod. Sci., 2016, 2(4), 226-238.

38 E. Ç. Salihi, J. Wang, D. J. L. Coleman and L. Šiller, Enhanced removal of nickel(II) ions from aqueous solutions by SDS- 
functionalized graphene oxide, Sep. Sci. Technol., 2016, 51(8), 1317-1327.

39 Z. N. Rajab, Electronic Spectroscopy of Some Transition Metal Ion Compounds in a New Ionic Liquids, Al-Nahrain University, 2012.

40 S. Dhananasekaran, R. Palanivel and S. Pappu, Adsorption of Methylene Blue, Bromophenol Blue, and Coomassie Brilliant Blue by $\alpha$-chitin nanoparticles, J. Adv. Res., 2016, 7(1), 113-124.

41 J. Xu, Z. Cao, Y. Zhang, Z. Yuan, Z. Lou, X. Xu, et al., A review of functionalized carbon nanotubes and graphene for heavy metal adsorption from water: Preparation, application, and mechanism, Chemosphere, 2018, 195, 351-364.

42 A. Khalid, M. Zubair and Ihsanullah, A Comparative Study on the Adsorption of Eriochrome Black $\mathrm{T}$ Dye from Aqueous Solution on Graphene and Acid-Modified Graphene, Arabian J. Sci. Eng., 2018, 43(5), 2167-2179.

43 S. Maji, A. Ghosh, K. Gupta, A. Ghosh, U. Ghorai, A. Santra, et al., Efficiency evaluation of arsenic(III) adsorption of novel graphene oxide@iron-aluminium oxide composite for the contaminated water purification, Sep. Purif. Technol., 2018, 197, 388-400. 